\title{
Second Language Learning in the Technology-mediated Environments
}

\author{
Zhonghao Zhou ${ }^{1}$ \\ ${ }^{1}$ Guangdong Civil Affairs School, Guangzhou, China \\ Correspondence: Zhonghao Zhou, Guangdong Civil Affairs School, Guangzhou, China.
}

Received: January 10, 2018

Accepted: February 8, $2018 \quad$ Online Published: February 11, 2018

doi:10.20849/aes.v3i1.307

URL: https://doi.org/10.20849/aes.v3i1.307

\begin{abstract}
Digital technologies are transforming formal educational practices that extend across space and time, blurring the traditional boundaries of learning in school and out of school. Multimedia software as well as most online materials delivered via combination of different media caters to learners with different cognitive styles. Technology-enhanced learning promotes active and ubiquitous learning, location-based learning, and the generation of learning communities. L2 learners with mobile devices have the advantage of interacting with peers anytime and anywhere.
\end{abstract}

Keywords: second language learning, technology, communication

\section{Introduction}

The development of technology is of great significance, and it can be said that nowadays citizens live in a technology-mediated environments. Such mediation requires the society to interact with technology symbols people need to be familiar with. Researchers have been discussing the importance of technology inclusion in society and have envisioned the skills and knowledge that this new scene would require citizens to acquire. The concerns in relation to education and technology aroused in scholars who foresaw a paradigm change in a near future (Gonzalez-Acevedo, 2016). In 1996, The New London Group met for the first time to discuss literacy pedagogy and the changes society was facing due to the inclusion of technology, globalization and socio-cultural diversity. The group was concerned about the need of the pedagogy of literacy to adapt to the new era and answer the requirements of such new multimodal and multimedia literacy.

Furthermore, the change of interaction with information and the new ways of learning is due to the change information access itself is going through. It is a great way of portraying not only how information access has changed but how information access has also changed the production limitations. In the technology-mediated society the production, reproduction and transformation of information is not restricted to published works but to anyone with access to basic technology resources. The concerns of the scholars in relation to the skills needed in the 21 st century grew as the technology mediated society changes the way to interact with information, people, learning and technology. As a consequence a wide range of terms, as media literacy, digital literacy, and information literacy appeared evidencing such concerns.

Research works indicate that technological development is very important and effective in learning a new language. Technology could promote language learning positively if they are used correctly, and it could provide chances to language learners and offers them unlimited resources and improve cooperative learning. Second language teachers should encourage the students to find suitable activities in order to be successful in language learning, and correct technological materials can be beneficial for students (Ilter, 2015). Technology-mediated learning experiences are becoming the norm for today's language learning. Numerous one-to-one tablet and laptop initiatives are promoted by schools and governments around the world. The number of students taking online and blended courses continues to increase. Helping students engage in learning is an important issue for research in instructional technology.

It is believed that how to best use technology to engage learners in meaningful and effective learning experiences is an important endeavor for researchers today. Research that improves the design of instruction needs good measures of student engagement to evaluate the efficacy of instructional interventions. Several publications review methods and identify issues that need to be addressed to improve the measurement of student engagement. These publications tend to focus on self-report measures of engagement, particularly quantitative scales. For example, observational measures implemented in classrooms where all students are present in one location 
would be challenging to arrange for an online course in which students learn separately and at a distance (Henrie, et al. 2015). Additionally, technology affords us with new methods to measure student engagement in ways both scalable and minimally disruptive to learning, such as using computer-generated data of user activity with a learning system.

Digital technologies are transforming formal educational practices that extend across space and time, blurring the traditional boundaries of learning in school and out of school. Researchers are increasingly documenting new technology-enriched socially shared learning activities that mediate students' engagement and learning opportunities across various timescales and spatial contexts. In these new technology-enriched infrastructures for learning, many of the traditional dichotomies concerning formal/informal, online/offline, and teacher-led/student-led activities have become more fluid and mixed. In some of the new pedagogical frameworks, the learning settings ranged from the formal school setting to more informal settings, such as the home, cinema, or streets. The students made observations and took photos in their daily encounters outside school and associated these photos with knowledge learned in class. The students' photos and other learning products were then discussed online among peers and in class facilitated by the teacher (Kumpulainen and Rajala, 2017). The researchers concluded from their studies that over time the students moved from acquiring content knowledge to developing the capacity to learn seamlessly across contexts.

In the technology-mediated learning activities, students' different identities, interests, and discourses have been identified as intersecting, creating opportunities and tensions for students' engagement and learning opportunities. It has also been pointed out how traditionally structured time-space configurations of school pose a challenge for students' engagement and learning within such new infrastructures. These studies have shown that students interpret and experience technology-mediated learning activity in varied ways and these interpretations mediate what resources and discourses students consider appropriate for the tasks at hand. One of the studies investigated Norwegian secondary school students' engagement in a social media site that involved chatting with other students, writing blogs, and sharing videos. The study revealed that the students displayed varied learner identities and associated orientations to the social media site as a space for learning.

The aim of this work is to explore the impact of integrating media technology in second language learning classrooms and to analyze how much it assists learners in acquiring language skills. It will focus on the potential of technology as a powerful tool for second language instruction and the challenge of training our teachers in its instructional applications.

\section{The Integration of Technology in Second Language Learning}

\subsection{Media Technology}

Over the past several decades, technology has become a fixture around the world. Its influence has permeated into all facets of life, including second language teaching. Integration of media technology began in the 1950s when small language schools began to use the phonograph, movies and the tape recorder as tools in second language teaching. In the $70 \mathrm{~s}$ and $80 \mathrm{~s}$, audio and video courses were improved through the added use of video projectors and slide shows. By the late $80 \mathrm{~s}$ and early $90 \mathrm{~s}$, language labs were part of many of the more expensive language schools throughout the world. However, by the mid 90 s many multimedia language programs became available for teachers on the Internet. In modern era of second language teaching, media technology such as video, pictures, animation, CDs or DVDs, internet, chat rooms and video conferencing and iPad have narrowed distance and turned the whole world into a global community (Ahmad, 2012). It provides opportunities to learners to converse not only with local community but with global community as well. It has revolutionized learning and teaching methodologies, thereby turning them more enjoyable and productive. Digital learning is delivering knowledge when and where it is needed, and it has been found that there is less teacher and more learner talk in computer classes. Furthermore, it changes teacher and students' roles and makes learning more students centered. Vision and hearing are the two dominant senses that media technology can provide to the students and present greater opportunities for learning linguistic inputs.

\subsection{Computer-mediated Communication (CMC)}

Computer-mediated communication (CMC) was originally supported by networked computers using traditional formats such as e-mail and chat rooms. Even with the incorporation of traditional CMC systems into virtual environments and innovations such as multi-user domains (MUDs), CMC systems have remained largely text-based. Accordingly, the study of communication or discourse within virtual environments has focused mainly on text-based CMC. Several researchers have studied text-based CMC to understand participants' communication forms, patterns, and functions. Other researchers have explored online text-based chat, categorizing non-verbal forms and functions by analyzing transcript excerpts. CMC, in forms such as the virtual 
chat features provided by early versions of virtual environments, has been predominantly text-based. The lack of non-verbal communication cues in these virtual environments severely hampers learners' social interaction, and also limits the sophistication of communication. As technologies have evolved, CMC forms have also evolved into synchronous voice-based CMC (SVCMC). With the advent of SVCMC tools, much of the communication within virtual environments has shifted from texting to talking (Shih, 2014). The new generation of SVCMC tools facilitates more sophisticated communication in terms of information depth, manners of communication, enhanced synchronicity, and user autonomy. As might be expected, the development of these SVCMC tools has had an impact on second language learning.

Communication strategies encompass both verbal and non-verbal employed to sustain communication. They can be used by language learners to manage communication problems and avoid breakdowns, in addition to facilitating the negotiation of meaning. Researchers have examined how communication strategies allow learners to compensate for insufficient competence, maintain conversation, and lead the conversation when appropriate. It has been noted that communication strategy use is crucial for advancing language learners' inter-language development. To classify communication strategy use, various researchers have conducted systematic analyses and provided communication strategy taxonomies. Taxonomy has been widely adopted in subsequent studies on communication strategy, and researchers have developed their own communication strategy taxonomies, many of which contain substantial overlap in terms of subcategories and descriptions.

\subsection{E-learning}

In language teaching E-Learning can offer an opportunity to include original texts and to update them in a simple way, to use audio recordings and video recordings done by native speakers. E-Learning gives students a chance of interactive spoken and written communication. People have paid a great attention to preparing and using online courses in second language teaching for many years. The courses are often prepared in cooperation of teachers and students of informatics subjects taught at the faculty. Therefore the courses are made-to-measure, adjusted to the needs of the faculty teachers and students as well. At the same time, by taking advantage of the students' ability to communication and also very good technical facilities of the school, the design of the online language courses is very simple. All lessons are organized in an identical way. Therefore they are well understandable, and the work with them is easy and purposeful. The courses are directed to practicing grammatical issues, to working with original target language texts, to listening to the texts (Hubackova, 2010). There are drilling tests with an answer key included in every lesson with the possibility of unlimited repetition of tests, fill-in-the-gap texts, videos and texts for listening. The listening exercises are completed with their textual wordings of extracts, which is very important for understanding the original texts. The listening texts and video-extracts are borrowed from target language web pages to offer the students the kind of speech of native speakers and to compensate the conversation with them partially at least. It is shown that the students had a keen interest in the online courses of the target language.

Technology-mediated environments for language learning moved quite rapidly from being more marginal, specialized places for language learning, relying on custom-made materials, to being more open spaces, closely linked to the everyday worlds and technologies of users. Within the formal learning settings of the course, the virtual chatting acted as a gateway to target language communities and provided an authentic and purposeful cross-cultural experience. At the same time research began to identify ways in which students were highly agentive in deploying everyday tools and technologies in the course of their language learning. In a bilingual collaborative project between students in Germany and New Zealand, for example, students collaborated using a wide range of communication tools, both voice and text, including chat, asynchronous discussion forums and wikis (White, et al. 2016). Those sites became personally meaningful dwelling places for their everyday lives, as well as for language learning, linked to time and place. It is believed that whether technology-aided learning become part of individuals' language learning environment depends on the strength of the boundaries which individuals have created for themselves as language learners.

\section{Computer-assisted Language Learning (CALL)}

Computer-Assisted Language Learning (CALL) is a relatively new and rapidly evolving academic field that explores the role of information and communication technologies in language learning and teaching. It includes a wide range of activities and initiatives in materials development, pedagogical practice, and research. CALL includes highly interactive and communicative support for listening, speaking, reading, and writing, including extensive use of the Internet. Materials development, pedagogy, and research in this field have developed in intellectual sophistication to the point where CALL should be considered as an independent academic field of study. CALL is sometimes regarded simply as a sub-section of computer assisted instruction (CAI), but because 
CALL deals specifically with language learning, it is both inherently multidisciplinary and academically substantive. CALL can be said to belong to the field of applied language studies and, within that, is most closely related to second language acquisition (SLA), which is itself a rapidly evolving discipline. CALL and SLA are related to sociolinguistics, pragmatics, discourse analysis, and psycholinguistics.

\subsection{The Goal of CALL}

The main goal of intelligent CALL is to prepare students for active citizenship in a global and networked society. It is essential for the students themselves to be able to find, evaluate and critically interpret information available on the Web, to create their 'texts' from their own selection of materials from a variety of sources. In teaching we will have to go behind how to decode texts, or understand them and pay increasing attention to how to explore and interpret the vast range of online texts. Another aspect to be considered relates to an effective online writing, since that is ubiquitous in the knowledge society and was reinforced by the advent of Web 2.0 (Martins, 2015). The development of a digital literacy is also one of the goals of teaching and learning second languages, and the ultimate purpose is that the learner becomes active, autonomous, independent and able to plan her/his active, conscious, and purposeful self-regulation of learning. This intelligent phase features the concept of multimodality, which refers not only to the variety of media available today and the different ways of constructing meaning, but also the possibility of combining these modes more easily in an orchestration of meanings.

CALL is a new field in both the computer and linguistics sciences. Linking both fields, it offers good promises to teachers, linguists, and computer researchers. With the growing sense of unity between linguists and computer scientists, some of the mysteries of language acquisition will be uncovered, which can help provide more effective and principled language teaching. The linguist can provide the theoretical assumptions of language learning, the efficient approaches, and methods required by the language learning and the acquisition process, while the computer scientist can help provide sophisticated means to meet the requirements generated by those approaches and methods. There are many peripheral applications for computers in the educational domain (Marzban, 2011). Language testing, language research, and school management, for instance, all offer scopes for computer applications. CALL programs help improve learning speed, individualized instruction, authenticity, efficiency, and administration. Linguists view CALL as a new device for testing current hypothesis and developing new ones accurately. The history of CALL suggests that computer can serve a variety of uses for language teaching. It can be a tutor which offers language drills or skill practice; a stimulus for discussion and interaction; or a tool for writing and research. These emerging technologies give learners great opportunities to engage in authentic conversation and expand their exposure to the target language. The social and learning impacts of these applications deserve great attention in the near future.

\subsection{The Stages of CALL}

In a research work trying to systematize different stages of CALL, there are several phases. The first phase, associated with behaviorist learning theories, is characterized by activities of stimulus-response and repetitive exercises. Next there is the communicative phase, which is based on a communicative approach to teaching and learning and the focus lies now on the effective use of language. Originality is encouraged and textual reconstruction activities and role-play are promoted. The integrative phase coincides with the development of multimedia technology and the emergence of new theories which argue that language learning is a social construction. According to this perspective, students should be confronted with rich and authentic learning environments.

Continuous developments in information technology have had strong implications in second language teaching and learning. The emergence and dissemination of the concept of CALL is attracting the increasing interest of teachers and researchers for this area of knowledge. The evolution of the concept is closely related to the findings in the area of information technology. The role of technology as a resource for instruction of second language learners is increasing as educators recognize its ability to create both independent and collaborative learning environments. In the eighties, the application of technology in language classrooms included the use of film, radio, television, language labs with audio and video tapes, computers, and interactive video. Various types of computer-assisted language learning also began to become more common. Although there were some innovative uses of software such as MacLang, the majority of CALL uses were limited, in form, to drill and practice exercises. As the technology advanced, we began to see more interactive uses of CALL as well as an increase in the integration of various media into the computer system.

\subsection{The Applications of CALL}

Computer technology has become more accessible to both individuals and schools. Moreover, our growing 
understanding of its potentials has encouraged a shift in emphasis from computer technology itself to its applications. That is, finding ways to use computers for enhancing teaching and learning has gained prominence in the research (Ghasemi, et al. 2011). Today, the use of multimedia, the Internet, and various forms of distance learning are wide spread. Interest in using them as tools to support language learning is growing, both from the perspective of a language educator and that of a language learner. Through the use of the Internet, word processors, multimedia, hypermedia, drill and practice programs, students can engage in individualized instruction designed to meet their specific needs and participate in cooperative projects that foster communication with peers in their classrooms and throughout the global community. This is indeed an important area and a current direction in second language teaching, which is under the discipline of applied linguistics.

Multimedia software as well as most online materials delivered via combination of different media caters to learners with different cognitive styles. Information technology benefits both the students as well as the teachers. Both get to know each other to enable the rapport normally associated with good teaching. It enables greater imaginative understanding through increased access to information and new ways of accessing the information. It enables the recording process to take place while it is being used. With the advent of the Internet, it can also be a medium of global communication and a source of limitless authentic materials. Findings from numerous studies suggest that the use of visual media supported vocabulary acquisition and reading comprehension and helped increase achievement scores. The technological advancements in the field of education should be constantly used by the students and teachers. The so called facilitators should strive hard to provide effective language education to students. It is time that we move to create a comprehensive, coherent language learning environment that reflects our enhanced knowledge of language acquisition, education and technology. The integration of computer technology into the communication environment has the potential to transform the students from passive recipients of information into active participants.

\section{Information and Communication Technology (ICT)}

Information and Communication Technology (ICT) stands for new multimedia technologies, including computer software, CD-ROM, the internet, television, film as well as internet-based project work, e-mail, chat, blogs, wikis, podcasts, and so forth. A large amount of research has been conducted to better comprehend the effect of ICT on students' language learning and demonstrates that the use of ICT in language classes increases the students' enthusiasm and achievement and also makes them stay longer on the task. Moreover, it is found that if students believed that ICT could help them in their long-term future, they would spend more time on using it. ICT can help students with intellectual disabilities to promote their communication skills and self-confidence. Furthermore, ICT increases students' computer literacy, strengthens their cultural awareness, and develops their social identity in the target culture (Hismanoglu, 2011). Of course, there are some negative points, including the expense which prevents ICT from being used as widely as desired, parents' doubts even fears about the vast amount of ICT use, insufficient time allocation due to pre-arranged syllabus, also lack of technical support dedicated to the use of ICT, and lastly teachers' in-confidence for their few skills on the new technologies.

\subsection{The Role of ICT}

The rapid progress of information and communication technologies is considered as one of the key factors of change in humankind society. Today, the rapid progress of information and communication technologies has been combined with different aspects of life, including its effect on education, research and communications. Progress and development in information and communication technology are considered as positive elements of change in higher education, and internet and network technology are used extensively in educational fields. Today, internet has become an instrument for searching information, social-international interactions and support of discoveries, and it has a fundamental role in the education process. Studies have shown that in spite of the rapid progress of information and communication technologies, these technologies are not used effectively in classrooms. Sometimes students do not know how to use internet effectively; even the instructors do not understand its use in educational schedules or in everyday classes (Ahmadi, 2011). It is found that while technology is mostly used in administration and researches, it is rarely used in education since including computer technologies in instructional process challenges the faculty members' abilities. According to performed researches, there are still a lot of faculty members who do not use information and communication technologies effectively in the process of teaching and learning. However, it is a fundamental need to help and encourage the faculty members to accept these technologies effectively and apply them in their education.

ICT can enhance language learners' target language and curriculum learning by providing opportunities to access information in different and helpful forms, for example, through multimedia, through key visuals, or through models and simulations. The access to meaning can be improved for learners through the variety of media 
available: e.g. speech and/or text, graphs, diagrams, video, graphics, etc. Using models, simulations and key visuals can help learners visualize complex or abstract processes and concepts. They can support learners to move from simple observational or naming language to the complex language of explanation, hypothesis, prediction and generalization. It may create opportunities for learners to refine, develop and store their language output, for example, using word processing programs to redraft, using publishing programs to present information, or using web cams to record their oral presentations. ICT allows learners to combine spoken, written, visual and graphic output which can support them to successfully express what is just beyond their current linguistic competence in the target language, and to develop further competence. Learners are more likely to develop and refine their ICT-based output than paper-based output, able to develop it collaboratively with more opportunities to examine their language output in detail.

ICT may create a context in the target language and show how it is used, for example through text tools, authoring programs or writing frames. Comparing learner versions between themselves and against models can help learners identify improvements they could make. It can support curriculum and L2 learning, for example through internet translation tools, electronic bilingual dictionaries, first language subject-related texts and explanations on the internet. ICT provides opportunities for learners to become autonomous learners and to practice their skills in particular areas of L2 through specific software or internet based research. Computer based L2 learning activities can increase confidence and competence in specific areas. They can be useful tools for independent study and autonomous learning. ICT may increase opportunities and motivation to communicate in L2, for example through email exchanges, video conferencing, virtual classrooms or web page authoring. Computer-mediated communication (CMC) increases the ways learners communicate, and communication can be less culturally and linguistically bias. Research suggests that CMC encourages L2 learners to take risk with language, to learn from the language of others and encourages different language structures. It can stimulate working, thinking and talking collaboratively which supports learners to process and embed language and curriculum learning. ICT as a stimulus can provide the context for this, and can be used to stimulate exploratory talk and encourage collaboration in the construction of learning.

\subsection{Technology Acceptance Model (TAM)}

In the degree to which students will use ICT tools, one pivotal factor is their acceptance of technology. The Technology Acceptance Model (TAM) is a commonly used model, and aims to predict the intention to use ICT. TAM is founded on the well-established Theory of Planned Behavior, which explains human behavior by stating that it is directly preceded by the intention to perform this behavior. Intention, in turn, is influenced by three factors: personal beliefs about one's own behavior, ones norms, and the amount of behavioral control one has. Building on this theory, TAM states that the intention to use ICT is influenced by two main factors: the perceived usefulness and the perceived ease of use. The former refers to the extent to which a person believes the use of ICT will, for example, enhance his or her performance on a course, and the latter is the perceived effort it would take to use a particular communication tool like a webcam (Giesbers, 2013). The development of advanced information and communication technologies (ICT) has changed the way teaching and learning are conceptualized and conducted. Technology-enhanced learning is a common practice nowadays, describing learning activities or environments that are mediated, supported, facilitated, or augmented by web-based technologies.

Technology-enhanced learning promotes active and ubiquitous learning, location-based learning, and the generation of learning communities. As ICT continue to develop, new learning methods evolve, requiring learners to be flexible in their ability to use them efficiently. Hence, technology acceptance and adoption, in various contexts, is a main factor of contemporary flexible thinking in learning. Following the need to examine an individual's ability to accept and adopt new technologies, the Technology Acceptance Model was generated. This model consists of four constructs: perceived ease of use, perceived usefulness, attitudes toward using technology, and behavioral intention (Barak and Levenberg, 2016). Perceived ease of use is the degree to which a person believes that using a particular system will be free from effort, while perceived usefulness signifies the degree to which a person believes that using a particular system will enhance their performance. Attitude toward using is the degree to which a person prefers a particular technology, and behavioral intention is the degree to which a person is open and willing to use a particular technology. Flexible thinkers are open to new experiences and therefore are more likely to accept and adopt new technologies.

Rapid changes in the way people communicate and construct knowledge require the ability to adapt to new situations. Adaptability refers to an individual's ability, skill, disposition, willingness, and/or motivation, to change or fit different task, social, and environmental features. In contemporary education, adaptability is thought of as an essential skill since students are required to use new learning methods, environments, and tools. 
One characteristic of adaptability is the willingness to be involved in an unfamiliar situation. This can be a new learning topic, a new learning environment, or a new problem to solve. As part of flexible thinking, adaptability allows a learner to engage with these unfamiliar situations in an efficient way. It explains students' ability to transfer what they have learned to new situations, since flexible learners are prepared to challenge the unknown and face the unfamiliar. In the context of collaboration and team work, flexibility and adaptability are related competences. Adaptive responses to changing demands and the ability to spontaneously restructure one's knowledge are important for a successful teamwork. Flexible thinkers adapt easily to varied roles, responsibilities, schedules, and contexts. They work effectively and respectfully with diverse teams by making necessary compromises to accomplish a common goal.

\subsection{Learners' Motivation and Attitude to Use ICT}

Research has shown that motivation is a key mediator for behavioral intention to use ICT. Only recently has the link between technology acceptance and motivation been made in the domain of e-learning, more specifically in computer-supported collaborative learning, by linking TAM with self-determination theory (SDT). Self-determination, which is understood as the extent to which learning is perceived to be self-steered and autonomous, has been found to be a dominant factor that influences learning behavior in various settings, including in e-learning settings. Self-determination is strongly related to motivation, and is specifically framed in terms of social and environmental factors that facilitate versus undermine intrinsic motivation. Intrinsically motivated learners are also referred to as autonomous, as they typically engage in learning because they find it enjoyable or challenging and they have an internally focused locus of causality. Extrinsically motivated learners are referred to as 'control oriented', as they feel they have limited control over their learning process. According to SDT, motivation is not a dichotomous construct where students either have an intrinsically or extrinsically directed drive. Instead, extrinsic motivation is perceived as a continuum of types differing in how close they are to intrinsic motivation and vice versa. Self-determination has been shown to explain differences in amount and quality of students' e-learning activities. The contributions to discussion forums in online courses have been found to be higher for more intrinsically motivated students.

Second language teachers cannot simply assume that the techniques, approaches and strategies that worked well in the traditional learning environment of the classroom can simply be successfully used in the environment of the ICT. Students' perceptions were found to influence the success of integration, specifically the amount of technology use, the ways in which the technology was used, and teachers' and students' expectations about learning. It is found that people's computer use was predicted by their reasons for use and that perceived usefulness was also strongly linked to this reason. According to Technology Acceptance Model, there is a significant impact on a user's attitude towards using the systems. Another research shows that second language teachers perceive that ICT enhances the need to know how to integrate it in teaching, helps their students understand the target language better, facilitates their students' language learning, enables their students to use real or authentic language with people and meets the individual language learning needs of their students. In addition to factors such as computer access, time constraints, individual computer skills and hardware issues, learner socio-cultural backgrounds, previous knowledge and learning experiences also contribute to their perceptions of the learning process. Only through students perceiving learning technologies as part of a learning context which encourages independence in learning and deep learning approaches are enhanced, the desirable learning outcomes would likely take place.

Integration of technology into language education has become an everyday occurrence. Educational multimedia courseware as resource materials to enhance the teaching and learning of the target language was produced extensively. This kind of courseware is used as a learning tool in the second language classroom with a hope that it could help in overcoming students' proficiency problem. It is hoped that by using the courseware, students' interest in learning the language could be gained and eventually their proficiency could be improved (Yunus, et al. 2010). In the past, the cost of computers and courseware greatly restricted the use of computers in education. Now, however, regardless of the cost, computers and courseware are becoming important tools for learning in institutions. Indeed, in the polytechnic, considerable pressure is being put on the second language lecturers to make use of the courseware marvels in their lesson as the cost of the courseware is rather expensive. With the use of the courseware in the second language classroom in the polytechnic, and, with the integration of ICT in the teaching of the subject, it is important to ensure that the courseware really supports the students' learning as a learning tool.

Once information and communication technologies (ICT) were implemented in education, language teachers have been in the forefront of using such technologies to facilitate language learning and teaching process. In the 21 st century, with the widespread use and application of ICT in education, the teachers' role in using ICT has 
been shifted from being the mere main knowledge providers to facilitators of learning languages via ICT. Accordingly, the technologies have also changed from being used mainly by teachers as presentation tools to supportive tools in language classes. From this perspective, teachers are the end-users and real agents in both technological plans and the subsequent implementation processes of ICTs in language learning and teaching.

\subsection{The Applications of ICT}

Nowadays, Information Communication Technology (ICT) is becoming increasingly important in education. One of the practical examples in teaching and learning language was GEMS Wellington Primary School which has introduced an innovative teaching methodology by using information and communications technology (ICT) equipment in second language teaching. The initiative is based on the suggestion where the integration of technology with education is needed to complement the efforts to boost the efficiency of second language training. The students made presentations about their learning experiences which included learning the different ICT equipments such as MP3 and MP4 player, digital cameras, digital camcorder, mobile phones and portable laptops in the target Language. For the outcomes, the learning process is very successful. One of the teachers said that learning second language using the latest ICT tools has revolutionized the teaching and learning practices. It has generated tremendous interest among non-native learners. They encourage the students to leverage the advantages of technology because it is important, both as a teaching tool and as an increasingly important part in their lives. Multimedia activities could be used in proper teaching and learning steps in the classroom especially for assigning students' homework and in class exercise (Lubis, et al. 2010). As part of learning process, homework and in-class exercises are given to students to help them in memorizing and revising what they have learned in classes. Assignments are also provided as a practice in helping students to solve problems and case studies. Multimedia presentations are usually used to describe a topic and illustrate it using visualization of objects and process. The multimedia activities are also able to test the explained matter using several prepared exercise as well and by applying this method, students could also improve their ICT knowledge.

Concerning the availability of the necessary technology, recent studies indicate that all Member States of the European Union as well as pre-accession countries are making remarkable effort to catch up and to bridge the new ICT. As to the technical support and time allocation, surveys reveal that ministries of education began to show a growing awareness of the need to address the question of providing specific support for ICT in SLT and also special teaching and learning programs are being developed, albeit most frequently taught and used in Europe. Regarding the families suspicions, it is the teacher's or instructor's task to endure that learners do not, for example, just surf the Web at random, but by directed within a specifically structured task, obtain the maximum benefit possible from time spent online. At this juncture, a shift of paradigm is necessary in teacher roles more like a facilitator, mentor, integrator of new media, researcher, designer of complex learning scenarios, collaborator, orchestrator of technology, learner and curriculum, learner and evaluator rather than a dominant and authority figure in the classroom.

In the age of ICT teachers and researchers have long been interested in uses of new technologies in second language teaching and learning. It argued that ICT may increase motivation, and is frequently linked with learner autonomy, which is defined as the ability to take charge of one's own learning. In other words, learners should be able to take all the decisions concerning their learning: determining targets and objectives, choosing contents and materials, selecting methods and techniques, organizing their learning, and assessing their progress. ICT thus seems to befit autonomy because it is claimed to provide greater freedom and flexibility to learn at one's own pace and convenience, whether within the context of a language course or beyond. It can contribute to lifelong learning, perhaps most apparent in use of the internet, which represents a worldwide library and resource centre where information can be accessed fast and efficiently: learners can thus benefit from a vast range of authentic language materials and resources which can be selected according to learning needs, aims, styles, strategies and preferences. ICT can be defined as a diverse set of technological tools and resources used to communicate, and to create, disseminate, store, and manage information. These technologies include computers, the Internet, broadcasting technologies, and telephony (Ghasemi and Hashemi, 2011). In recent years there has been a groundswell of interest in how computers and the Internet can best be harnessed to improve the efficiency and effectiveness of education at all levels and in both formal and non-formal settings. But ICTs are more than just these technologies; older technologies such as the telephone, radio and television, although now given less attention, have a longer and richer history as instructional tools. Moreover, different technologies are typically used in combination rather than as the sole delivery mechanism. 


\section{Mobile learning}

\subsection{Mobile Technologies}

Mobile learning has recently emerged as a new type of learning model which allows learners to obtain learning materials anywhere and anytime using mobile technologies and the internet. Given the global fact that more and more students use mobile devices such as notebooks, net-books, tablets, 4G mobile phones, digital cameras, MP3 players, and personal digital assistants (PDAs), there is now a growing interest in the potential role of mobile technology in supporting students formally both in and outside the classroom. In fact, many studies across disciplines have investigated the positive effects of using mobile technologies on education $(\mathrm{Oz}, 2014)$. Thus, the integration of mobile technology into higher education is important in providing students with a higher quality of education and contributing to higher national productivity growth.

Mobile learning can be broadly defined as the exploitation of ubiquitous handheld technologies, together with wireless and mobile phone networks, to facilitate, support, enhance and extend the reach of teaching and learning. Mobile learning can take place in any location, at any time, including traditional learning environments such as classrooms as well as in workplaces, at home, in community locations and in transit. Mobile technologies include mobile phones, PDAs, MP3/ MP4 players, handheld gaming devices, Ultra-mobile PCs (UMPCs), mini notebooks or net-books, handheld GPS, and specialist portable technologies used in science labs, engineering workshops. Mobile learning involves connectivity for downloading, uploading and/or online working via wireless networks, mobile phone networks or both, and linking to institutional systems e.g. virtual learning environments (VLEs) and management information systems (MIS). Mobile learning is currently the most useful tool in ICT world. It is believed that mobile learning could be an essential factor in involving L2 learning. As mobile phones combine PDA functions with cameras, video and MP3 players, and as tablets combine the portability of PDAs with the functionality of desktops, the world of learning becomes more mobile, more flexible and more exciting (Hashemi, et al. 2011). What makes mobile technology so intriguing is that it has an affinity with movement between indoors and outdoors, across formal and informal settings, allowing learners to lead at least some of the way. If language learners' preferences and needs can be allowed to have a bearing on what is learnt, mobile technologies have a clear role to play in realizing such an objective.

\subsection{Three Aspects of Mobile Learning}

Mobile learning refers to any educational provision where the sole or dominant technologies are hand-held or palmtop devices. A mobile device is any device that is small, autonomous and unobtrusive enough to accompany us in every moment. In accordance with the developmental history of mobile learning, three aspects can be specified for this type of learning: mobility of technology; mobility of learning, and mobility of learner. The focus of mobility on learning is on the extensive use of mobile devices for learning outside the classroom. The third aspect focuses on the mobility of the learner, the design or the appropriation of learning spaces and on informal learning and lifelong learning. The swift development of mobile phones in the last decades from simple phones to smart-phones, which can serve as a mini-computer, telephone, or camera, and transfer data as well as video and audio files, has made mobile phones efficient learning tools.

Mobile learning is a type of learning that takes place with the help of mobile devices and simply means learning anywhere and at any time. While at the beginning, mobile learning focused on the role of mobile technologies and devices in education, in the recent years mobile learning is characterized with the mobility of the user and the informal learning that happens out of the classroom. In this case, any portable and palmtop devices such as portable media player devices, tablets, and mobile phones contribute to mobile learning. From among the portable technological tools, mobile phones are the most commonly used devices for learning, and due to their portability and accessibility, many scholars now consider using them in the educational settings for learning and teaching purposes. Research shows that mobile phones can be used to leverage instruction, empower place-based learning, and amplify learning (Rahimi and Miri, 2014). Mobile learning has certain benefits for language classes as well and allows language teachers to offer access to authentic content, communicative language practice, and task completion.

\subsection{The Advantages of Mobile Learning}

The advantages of mobile-based L2 learning lie in its technology, including technologically advanced devices and functions, accessibility of learning resources that can be obtained anytime and anywhere, and the use of various applications for studying. These technological aspects tend to be stressed in examining the effectiveness of mobile learning. Learners have adopted mobile technological affordances more readily than those of personal computers, because mobile devices have already become such requisite tools for life daily in many countries that students have their own smart-phones or other mobile devices. L2 learners with mobile devices have the 
advantage of interacting with peers anytime and anywhere with the resources they bring from their own everyday life-worlds, which can make their L2 learning more contextualized and effective. It is shown that mobile devices have become indispensable tools for daily life because of their portability, the convergence of technologies, and the decreasing cost for the devices and services.

Numerous studies also indicate that students in higher education have positive attitudes towards and perceptions about m-learning, and they are increasingly taking advantage of many functions in their mobile devices. Access to technology, ownership and connectivity are among critical success factors for integrating m-learning in higher education. It can be asserted that every individual in higher education owns a mobile phone and a great majority of students own portable computers. The increasing popularity and many mobile applications developed have supported second language teaching. It was found out that around $90 \%$ of distance-education students and faculty owned laptops and cellular phones and those who owned other handheld mobile devices ranged from $10 \%$ to $47 \%$. These findings revealed that students often used mobile devices for emails, file transfer, and multimedia messages, and it suggests that the participants were ready for m-learning, mostly through laptops and cellular phones.

\section{Conclusion}

Technology represents a growing and rapidly evolving practice with potential benefits on students. In situations where the teacher and the classroom represents the only environment for second language acquisition and practice, asynchronous Web 2.0 tools offer students an alternative venue for additional interesting and engaging activities, ensure student-centeredness and autonomy as well as interaction and connectivity, and provide opportunities to practice reading, writing, speaking and listening outside the classroom walls at their own pace, in real life-semblance and safe environments. Second language teachers were among the first to recognize the benefits deriving from employment of the social networking tools in second language acquisition and established the first communities of practice for continuous professional development and dissemination of best practices.

Innovative and immersive technologies may transform conventional ways of teaching and learning. By collaborating with peers in immersive learning environments, students can deepen their understanding of the subject matter, transfer knowledge to real-world contexts, and develop a sense of belonging through peer scaffolding and virtual community building. The avatar-based environment as a playful, less threatening sphere also boosts confidence, heightens engagement, and stimulates risk-taking more than a $2 \mathrm{D}$ text-based setting. It is commonly agreed that language learners' immersion in a country where they are exposed to authentic and rich language input of the target culture is most conducive to second language acquisition (SLA). Nevertheless, the reality is that not everyone can afford the cost of traveling to a country where the target language is spoken, let alone stay there for an extended period of time (Chen, 2016). With the help of technology, it is possible to provide a dynamic space for language learners to work on authentic, interactive problem-solving tasks. Features afforded by technology-based learning, such as task simulation, real-time collaboration, identity exploration, and flexible multi-modality, can foster intercultural communication competence and negotiation of meaning; reinforce engagement, learning autonomy, and sense of belonging during task-based interaction; enhance language acquisition through synchronous multimodality; and facilitate real-world task delivery that transcends physical boundaries.

\section{Reference}

Ahmad, J. (2012). English Language Teaching (ELT) and Integration of Media Technology. Procedia-Social and Behavioral Sciences, 47, 924-929. https://doi.org/10.1016/j.sbspro.2012.06.758

Ahmadi, S., Keshavarzi, A., \& Foroutan, M. (2011). The Application of Information and Communication Technologies (ICT) and its Relationship with Improvement in Teaching and Learning. Procedia-Social and Behavioral Sciences, 28,475-480.https://doi.org/10.1016/j.sbspro.2011.11.091

Barak, M., \& Levenberg, A. (2016). Flexible thinking in learning: An individual differences measure for learning in technology-enhanced environments. Computers \& Education, 99, 39-52. https://doi.org/10.1016/j.compedu.2016.04.003

Chen, J.C. (2016). The crossroads of English language learners, task-based instruction, and 3D multi-user virtual $\begin{array}{lllll}\text { learning in Second Life. Computers \& Education, } & \text { 102, }\end{array}$ 152-171.https://doi.org/10.1016/j.compedu.2016.08.004

Ghasemi, B., \& Hashemi, M. (2011). ICT: New wave in English language learning/teaching. Procedia Social and Behavioral Sciences, 15, 3098-3102. https://doi.org/10.1016/j.sbspro.2011.04.252

Ghasemi, B., Hashemi, M., \& Bardine, S.H. (2011). The capabilities of computers for language learning. 
Procedia-Social and Behavioral Sciences, 28, 58-62. https://doi.org/10.1016/j.sbspro.2011.11.012

Giesbers, B., Rienties, B., Tempelaar, D., \& Gijselaers, W. (2013). Investigating the relations between motivation, tool use, participation, and performance in an e-learning course using web-video conferencing. Computers in Human Behavior, 29, 285-292. https://doi.org/10.1016/j.chb.2012.09.005

Gonzalez-Acevedo, N. (2016). Technology-enhanced-gadgets in the Teaching of English as a Foreign Language to Very Young Learners. Procedia-Social and Behavioral Sciences, 232,507-513. https://doi.org/10.1016/j.sbspro.2016.10.070

Hashemi, M.M., Azizinezhad, V., \& Nesari, A.J. (2011). What is Mobile Learning? Challenges and Capabilities. Procedia-Social and Behavioral Sciences, 30, 2477-2481. https://doi.org/10.1016/j.sbspro.2011.10.483

Henrie, C.R., Halverson, L.R., \& Graham, C.R. (2015). Measuring student engagement in technology-mediated learning: A review. Computers \& Education, 90,36-53. https://doi.org/10.1016/j.compedu.2015.09.005

Hismanoglu, M. (2011). The integration of information and communication technology into current ELT course books: a critical analysis. Procedia Social and Behavioral Sciences, 15, 37-45. https://doi.org/10.1016/j.sbspro.2011.03.048

Hubackova, S. (2010). Foreign language teaching with WebCT support. Procedia Social and Behavioral Sciences, 3,112-115.https://doi.org/10.1016/j.sbspro.2010.07.020

Ilter, B.G. (2015). How does technology affect language learning process at an early age?. Procedia-Social and Behavioral Sciences, 199,311-316. https://doi.org/10.1016/j.sbspro.2015.07.552

Kumpulainen, K., \& Rajala, A. (2017). Negotiating time-space contexts in students' technology-mediated interaction during a collaborative learning activity. International Journal of Educational Research, 84, 90-99. https://doi.org/10.1016/j.ijer.2016.05.002

Lubis, M.A., Yunus, M.M., \& Embi, M.A. (2010). ICT and systematic steps in teaching and learning language in the classroom. Procedia Social and Behavioral Sciences, 9, 1055-1061.https://doi.org/10.1016/j.sbspro.2010.12.285

Martins, M.L. (2015). How to effectively integrate technology in the foreign language classroom for learning and collaboration. Procedia-Social and Behavioral Sciences, 174, 77-84. https://doi.org/10.1016/j.sbspro.2015.01.629

Marzban, A. (2011). Improvement of reading comprehension through computer-assisted language learning in Iranian intermediate EFL students. Procedia Computer Science, 3, 3-10.https://doi.org/10.1016/j.procs.2010.12.003

Oz, H. (2014). Prospective English Teachers' Ownership and Usage Of Mobile Devices As M-Learning Tools. Procedia-Social and Behavioral Sciences, 141, 1031-1041.https://doi.org/10.1016/j.sbspro.2014.05.173

Rahimi, M., \& Miri, S.S. (2014). The Impact of Mobile Dictionary Use on Language Learning.Procedia-Social and Behavioral Sciences, 98, 1469-1474. https://doi.org/10.1016/j.sbspro.2014.03.567

Shih, Y. (2014). Communication strategies in a multimodal virtual communication context.System, 42, 34-47. https://doi.org/10.1016/j.system.2013.10.016

White, C., Direnzo, R., \& Bortolotto, C. (2016). The learner-context interface: Emergent issues of affect and identity in technology-mediated language learning spaces. System, 62, 3-14. https://doi.org/10.1016/j.system.2016.06.008

Yunus, M.M., Hashim, H., Embi, M.A., \& Lubis, M.A. (2010). The utilization of ICT in the teaching and learning of English: 'TellMe More'. Procedia Social and Behavioral Sciences, 9, 685-691.https://doi.org/10.1016/j.sbspro.2010.12.218

\section{Copyrights}

Copyright for this article is retained by the author(s), with first publication rights granted to the journal.

This is an open-access article distributed under the terms and conditions of the Creative Commons Attribution license (http://creativecommons.org/licenses/by/4.0/). 